\title{
Influence of ABO Blood Group on Fibrinogen Levels and Platelet Count in Apparently Healthy Nigerian Subjects
}

\author{
Okeke $\mathrm{CO}^{*}$ and Iloka VC
}

Department of Medical Laboratory Science, Faculty of Health Sciences and Technology, College of Health Sciences, Nnamdi Azikiwe University, Nigeria

*Corresponding author: Dr. Chizoba Okeke, Department of Medical Laboratory Science, Faculty of Health Sciences and Technology, College of Health Sciences, Nnamdi Azikiwe University, Nnewi Campus P.M.B. 5001 Anambra State, Nigeria, Tel: +23-470-3348-4245

\begin{abstract}
Background: A close association has been shown to exist between $A B O$ blood type and the risk of some diseases with non-O $(A, B$, or $A B)$ individuals having an increased differential disposition to thrombotic disorders.

Objective: The present study evaluated the fibrinogen levels and platelet count in subjects of different $\mathrm{ABO}$ blood groups with the view of ascertaining if disparity exists in the levels of fibrinogen and platelet count amongst the different $\mathrm{ABO}$ blood groups.

Methods: A total of hundred (100) apparently healthy young adult male and female participants comprised of 25 subjects of blood group $A, B, A B$ and $O$ respectively were recruited for this study. Five milliliters of blood was collected and used for the estimation of fibrinogen levels, platelet count and $\mathrm{ABO}$ blood grouping using standard laboratory methods. Statistical package for social science (SPSS) version 20 was employed in the analysis of the data.

Results: Blood group $\mathrm{O}$ individuals has a significantly lower platelet count compared to those of blood group A $(157.56 \pm 23.21 \mathrm{Vs}$ $188.92 \pm 46.94 ; P=0.041$ ). However, the mean plasma fibrinogen level did not differ significantly among the different $A B O$ blood groups $(P>0.05)$ respectively. Furthermore, there were no significant gender differences in the mean plasma fibrinogen level and platelet count of participants of various $A B O$ blood groups $(P>$ 0.05 ). In blood group $A$ individuals, there was a significant positive correlation between Fibrinogen level and platelet count $(r=0.385$; $p=0.048$ ). However, there were no significant correlations observed between these parameters in the other $A B O$ blood groups $(P>0.05)$.
\end{abstract}

Conclusion: Blood group $\mathrm{O}$ individuals may be more predisposed to thrombocytopenia than blood group $\mathrm{A}$ individuals.

\section{Keywords}

Platelet count, Fibrinogen, ABO blood group, Thrombocytopenia

\section{Introduction}

In 1901, Landsteiner identified ABO blood groups as the first recognized human blood group system. The clinical significance of $A B O$ blood type extends beyond transfusion medicine and solid organ/hematopoietic transplantation. The $A B O$ blood group is determined by the presence of $A$ and $B$ antigens on the surface of the red blood cells (RBCs). In addition to RBCs, these antigens are widely expressed on the membranes of a wide variety of cells, including platelets, vascular endothelium and epithelium, as well as in saliva and body fluids [1]. The ABH blood group antigens consist of terminal carbohydrate molecules which are synthesized by the sequential action of the $A B O$ glycosyltransferases [2]. The frequency of the $A B O$ blood groups varies among different populations in the world with the highest frequency of the A phenotype found mainly in Northern and Central Europe, B phenotype in Central Asia while Blood group $O$ is the most frequent phenotype globally, with parts of Africa and Australia showing highest frequencies [3].

Numerous reports have suggested important associations between $\mathrm{ABO}$ blood groups and various diseases, for example, gastric cancer, periodontal diseases and cardio metabolic diseases [1,2,4]. A close relationship exists between $A B O$ blood type and the risk of venous thromboembolism $[5,6]$. In both arterial and venous thromboembolism, non- $\mathrm{O}(\mathrm{A}, \mathrm{B}$, or $\mathrm{AB})$ individuals show significantly increased risk $[7,8]$, whereas group $O$ individuals have more pronounced inherited bleeding tendency [9].

The $A B O$ blood group is known to influence haemostasis because it is a major determinant of the von

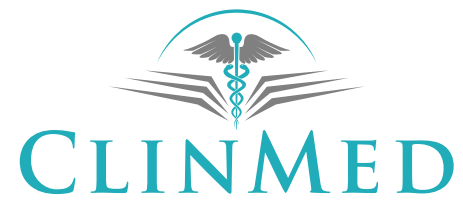

INTERNATIONAL LIBRARY

Citation: Okeke CO, lloka VC (2020) Influence of ABO Blood Group on Fibrinogen Levels and Platelet Count in Apparently Healthy Nigerian Subjects. Int J Blood Res Disord 7:054. doi.org/10.23937/24695696/1410054

Accepted: July 23, 2020: Published: July 25, 2020

Copyright: (C) 2020 Okeke CO, et al. This is an open-access article distributed under the terms of the Creative Commons Attribution License, which permits unrestricted use, distribution, and reproduction in any medium, provided the original author and source are credited. 
Willebrand factor (vWF) and FVIII plasma levels [10]. Liu, et al. [11] and Wang, et al. [12] found that plasma vWF levels and FVIII activity were significantly increased in individuals with non-O type blood compared with those with type $\mathrm{O}$ blood groups. Also a study by Okeke, et al. [13], showed that individuals with blood group 0 showed a significantly higher APTT value compared to blood groups $A, B$, and $A B$ while blood group $A$ individuals showed a significantly higher PT value compared to blood groups $\mathrm{O}, \mathrm{B}$, and $\mathrm{AB}$.

Platelet count and fibrinogen are parameters that play major roles in haemostasis. Platelet is the central mediator of primary haemostasis that involves platelet adhesion, release of granules and aggregation resulting in the formation of a platelet plug. They are small, irregularly-shaped cells, 2-4 $\mu \mathrm{m}$ in diameter, which are derived from fragmentation of precursor megakaryocytes. The average lifespan of a platelet is between 8 and 12 days. Platelets play a fundamental role in hemostasis and are a natural source of growth factors [14]. According to Zhong, et al. [15] ABH antigens are expressed on both platelet membrane lipids and platelet glycoproteins, and these may influence platelet interactions with fibrinogen, thereby modulating platelet aggregation and platelet-driven thrombosis. Fibrinogen is an essential component of the blood coagulation system, being the precursor of fibrin. It is one of the coagulation factors and plays a vital role in secondary haemostasis. It is converted to fibrin by the action of thrombin leading to the formation of fibrin clot which is stabilized by factor XIII. It is a soluble glycoprotein found in the plasma, with a molecular weight of 340 kDa [16]. Fibrinogen plays a vital role in a number of physiopathological processes in the body, including inflammation, atherogenesis and thrombogenesis. Decreased levels of fibrinogen are associated with an increased risk of bleeding [17]. Increased fibrinogen levels are postulated to enhance thrombus formation by altering the kinetics of the coagulation cascade, resulting in increased fibrin formation [18].

Since both Fibrinogen and platelet are known to play a role in haemostasis and a number of previous studies has identified a link between $A B O$ blood group and haemostatic differences in individuals this study was therefore designed to assess the influence of differences in $A B O$ blood group on the levels of Fibrinogen and platelet count.

\section{Material and Methods}

\section{Study site}

This study was carried out at College of Health Sciences, Nnamdi Azikiwe University, Anambra State, Nigeria. The College is a multi-faculty college comprising the Faculties of Health Sciences and Technology, Basic Medical Sciences and Medicine with each faculty having many academic departments. The college has a popula- tion of over 2000 students. The laboratory testing was done in Hematology Laboratory of Nnamdi Azikiwe University Teaching Hospital, Nnewi, Anambra State.

\section{Study design}

This is a cross sectional study designed to evaluate the levels of fibrinogen and platelet count in subjects of different $A B O$ blood groups.

\section{Study population}

The population comprised apparently healthy male and female undergraduate students of College of Health Sciences, Nnamdi Azikiwe University.

\section{Sample size calculation and sampling technique}

Sample size was calculated using $\mathrm{G}^{*}$ Power software (version 3.0.10) Universitat Dusseldorf Germany. Power analysis for one-way analysis of variance with four (blood) groups was conducted in $\mathrm{G}^{*}$ Power to determine a sufficient sample size using an alpha of 0.05, a power of 0.90 , and a large effect size $(f=0.40)$. Based on these, the calculated total sample size of 96 has $90 \%$ power to detect a difference of 0.40 at a significance level of 0.05 . A total of 100 subjects comprising 25 subjects belonging to each of the four blood groups (namely blood groups $A, B, A B$ and $O$ ) were recruited for this study. They were undergraduate students aged 18 to 28 years (with mean age of $23.6 \pm 4.4$ years) drawn from various faculties and departments in the College of Health Sciences, Nnamdi Azikiwe University. The individuals were recruited using a convenience sampling technique in which individuals that meets the inclusion criteria were recruited consecutively until the sample size was attained.

\section{Inclusion criteria}

Apparently healthy adult subjects of both genders.

\section{Exclusion criteria}

Those excluded from this research work included; individuals with known bleeding disorders, those who were sick or have been transfused with blood in the previous 3 months, smokers and individuals who refused to give their consent.

\section{Ethical consideration}

The ethical approval for this research was obtained from Ethics Committee of Faculty of Health Sciences and Technology, Nnamdi Azikiwe University in accordance with the Helsinki declaration by the World Medical Association (WMA) on the ethical principles for medical research involving human subjects.

\section{Informed consent}

Informed consent was sought and obtained from the subjects before sample collection.

\section{Sample collection and analysis}

Five milliliters $(5 \mathrm{ml})$ of venous blood was collected 
Table 1: Gender distribution of the subjects.

\begin{tabular}{|l|l|l|l|}
\hline & Male & Female & Total \\
\hline Blood group & Frequency (\%) & Frequency (\%) & Frequency (\%) \\
\hline O & $20(80.0)$ & $5(20.0)$ & $25(100.0)$ \\
\hline A & $12(48.0)$ & $13(52.0)$ & $25(100.0)$ \\
\hline B & $11(44.0)$ & $14(56.0)$ & $25(100.0)$ \\
\hline AB & $15(60.0)$ & $10(40.0)$ & $25(100.0)$ \\
\hline Total & $58(58.0)$ & $42(42.0)$ & $100(100.0)$ \\
\hline
\end{tabular}

Table 2: Comparison of platelet count and fibrinogen levels among the different $A B O$ blood groups.

\begin{tabular}{|l|l|l|}
\hline Blood Group & Platelet $\left(\mathbf{x} \mathbf{1 0}^{\mathbf{}}\right)$ & Fibrinogen \\
\hline$O(n=25)$ & $157.56 \pm 23.21$ & $331.92 \pm 53.76$ \\
\hline$A(n=25)$ & $188.92 \pm 46.94$ & $313.00 \pm 70.92$ \\
\hline$B(n=25)$ & $164.84 \pm 32.26$ & $329.40 \pm 63.98$ \\
\hline$A B(n=25)$ & $178.60 \pm 54.90$ & $288.92 \pm 46.53$ \\
\hline$F(P)$ Value & $2.89\left(0.040^{*}\right)$ & $2.76(0.046)$ \\
\hline$O$ vs. A p-value & $0.041^{*}$ & 0.676 \\
\hline$O$ vs. B p-value & 0.924 & 0.999 \\
\hline$O$ vs. AB p-value & 0.278 & 0.058 \\
\hline A vs. B p-value & 0.172 & 0.765 \\
\hline A vs. AB p-value & 0.813 & 0.484 \\
\hline B vs. AB p-value & 0.641 & 0.083 \\
\hline
\end{tabular}

${ }^{*}$ Statistically significant at $p<0.05$

by standard venepuncture from the individuals asceptically, $3 \mathrm{ml}$ was dispensed into EDTA container for ABO blood grouping and platelet count while $2 \mathrm{ml}$ was dispensed into $0.22 \mathrm{ml}$ of $3.2 \%$ trisodium citrate sample container. The blood was mixed and spun and platelet poor plasma separated for use in fibrinogen assay.

\section{Method for $\mathrm{ABO}$ blood grouping}

The $A B O$ blood grouping was done by the tile method using commercially prepared antisera (namely anti-A, anti- $B$ and anti-AB). A drop of anti-A, $-B$, and $-A B$ was placed on a white pitted tile, and a drop of blood was placed on each of the antisera. It was mixed well and rocked gently and observed for agglutination. A control was set up by adding standard cells to each antiserum in separate square.

\section{Procedure for platelet count}

This was done by the manual method using $1 \%$ Ammonium oxalate as diluent and Improved Neaubauer counting chamber for cell count. A 1 in 20 dilution of blood was made by adding $0.02 \mathrm{ml}$ of blood to $0.38 \mathrm{ml}$ of $1 \%$ Ammonium oxalate in a clean tube and mixed properly. The cover slip was tightly fixed to the Improved Neaubauer counting chamber, the chamber was charged with the suspension using a clean Pasteur pipette, and placed in a petri dish containing a piece of moist filter paper and covered for 20 minutes to allow the cell settle then using $40 x$ objective and eyepiece, the cell present was counted in the 5 of $0.04 \mathrm{~mm}$ area that is 4 outer square of $0.04 \mathrm{~mm}^{2}$ and the central one. The platelet count was calculated as appropriate.

\section{Measurement of fibrinogen level}

The test (platelet poor) plasma was diluted 1:10 in buffer and incubated at $37^{\circ} \mathrm{C}$, phospholipids and thrombin were added followed by Calcium (all pre-warmed to $37^{\circ} \mathrm{C}$ ). On the addition of the Calcium, timing begun. The time taken for the clot to form was compared to a calibration curve and the fibrinogen concentration determined.

\section{Statistical analysis}

Statistical package for social science (SPSS) version 20 was used for the data analysis. Results were expressed as mean \pm standard deviation and parameters was compared between different groups using independent $t$-test while One-way analysis of variance (ANOVA) was used for comparison of parameters among groups. Correlation was done using pearson correlation and level of significance was set at $\mathrm{P}<0.05$.

\section{Results}

About $58 \%$ of the participants were males and $42 \%$ were females. Majority of the blood group $\mathrm{O}(80 \%)$ and blood group $A B(60 \%)$ subjects were males while majority of the blood group B (56\%) and A (52\%) were females respectively (Table 1 ).

There was a significant decrease in platelet count in blood group $O$ participant when compared with the value obtained in participants of $A$ blood group (157.56 \pm 23.21 Vs $188.92 \pm 46.94 ; p=0.041$ ). However, posthoc comparison between other blood groups showed no significant difference platelet count $(p>0.05)$. Also, there was no significant difference in the mean fibrinogen levels of participants belonging to different blood groups $(p>0.05)$ (Table 2$)$.

There was no significant difference in the mean levels of platelet count and fibrinogen obtained in the male participants when compared with values obtained in female participants respectively $(p>0.05)$ (Table 3$)$.

The mean levels of parameters (platelet and fibrinogen) studied did not differ significantly when compared between various blood groups in male and female participants studied $(p>0.05$ ) (Table 4). 
Table 3: Comparison of platelet count and fibrinogen level between male and female subjects.

\begin{tabular}{|l|l|l|}
\hline Gender $(\mathbf{n})$ & Platelet $\left(\mathbf{x} 10^{9} / \mathbf{l}\right)$ & Fibrinogen \\
\hline Male $(\mathrm{n}=58)$ & $170.88 \pm 41.68$ & $313.84 \pm 64.97$ \\
\hline Female $(\mathrm{n}=42)$ & $174.69 \pm 43.75$ & $318.52 \pm 55.98$ \\
\hline t-value & 0.442 & 0.376 \\
\hline P-value & 0.66 & 0.708 \\
\hline
\end{tabular}

Table 5: Correlation of fibrinogen level and platelet count among the blood groups.

\begin{tabular}{|l|l|l|l|}
\hline Blood Group & Correlation & r-value & P-value \\
\hline$O(n=25)$ & Fibrinogen vs. Platelet & -0.174 & 0.406 \\
\hline$A(n=25)$ & Fibrinogen vs. Platelet & 0.385 & $0.048^{*}$ \\
\hline B $(n=25)$ & Fibrinogen vs. Platelet & 0.229 & 0.271 \\
\hline$A B(n=25)$ & Fibrinogen vs. Platelet & -0.029 & 0.892 \\
\hline
\end{tabular}

*Statistically significant at $p<0.05$

Table 4: Comparison of parameters between male and female subjects among the different blood groups.

\begin{tabular}{|l|l|l|l|}
\hline Blood Group & Gender & Platelet $\left(\mathbf{x} 1 \mathbf{9}^{\mathbf{l}}\right)$ & Fibrinogen \\
\hline Blood group O & Male $(\mathrm{n}=\mathbf{2 0})$ & $159.45 \pm 22.56$ & $330.40 \pm 60.11$ \\
\hline & Female $(\mathrm{n}=5)$ & $150.00 \pm 26.93$ & $338.00 \pm 10.95$ \\
\hline & t-value & 0.808 & 0.277 \\
\hline & P-value & 0.427 & 0.784 \\
\hline Blood group A & Male $(\mathrm{n}=12)$ & $176.50 \pm 42.24$ & $301.25 \pm 86.26$ \\
\hline & Female $(\mathrm{n}=13)$ & $200.38 \pm 49.75$ & $323.84 \pm 54.51$ \\
\hline & t-value & 1.288 & 0.79 \\
\hline & P-value & 0.21 & 0.438 \\
\hline \multirow{3}{*}{ Blood group B } & Male $(\mathrm{n}=11)$ & $167.18 \pm 35.01$ & $340.90 \pm 52.57$ \\
\hline & Female $(\mathrm{n}=14)$ & $163.00 \pm 31.15$ & $320.35 \pm 72.33$ \\
\hline & t-value & 0.316 & 0.791 \\
\hline & P-value & 0.755 & 0.437 \\
\hline & Male $(\mathrm{n}=15)$ & $184.33 \pm 60.71$ & $282.00 \pm 47.66$ \\
\hline & Female $(\mathrm{n}=10)$ & $170.00 \pm 46.55$ & $299.30 \pm 45.16$ \\
\hline & t-value & 0.631 & 0.907 \\
\hline & P-value & 0.534 & 0.374 \\
\hline
\end{tabular}

There was a weak but significant positive correlation between fibrinogen level and platelet count in blood group A participants $(r=0.385 ; p=0.048)$ (Table 5).

\section{Discussion}

The present study evaluated the fibrinogen levels and platelet count in subjects of different $A B O$ blood groups with the view of ascertaining if disparity exists in the levels of platelets and fibrinogen amongst the different $A B O$ blood groups as this may provide possible explanation for previous findings especially in $A B O$ differential disposition to thrombotic disorders.

The mean platelet count was found to be significantly lower in individuals of blood group $O$ than in individuals of $A$ blood group. Though in comparison to the reference range in literature $\left(150\right.$ to $\left.400 \times 10^{9} / \mathrm{I}\right)$ the levels were normal in this study, this may be suggestive of a likelihood of thrombocytopenia in individuals of $\mathrm{O}$ blood group than A blood group. Several studies have shown increased risk of thrombosis in individuals belonging to the non-O (A, $B$ and $A B)$ blood type [19]. The finding of this study however is in contrast with the report of Ajayi, et al. [20] who observed that blood group AB had significantly higher values of Platelet counts when compared with other blood groups. Aside the significant difference obtained between blood group $O$ and $A$, there were no significant differences in the mean platelet count when compared between individuals of the other blood groups. This is in consonance with the findings of a previous study that reported no significant differences in the mean platelet count between the different $A B O$ blood groups [21].

Our finding showed no statistically significant difference in the mean level of plasma fibrinogen when compared among the participants of different $A B O$ blood groups. This is in consonance with the report of previous studies $[12,22]$. However, contrary to the result obtained in this study in which there was a non-significant lower fibrinogen level in those with blood group $A B$ compared to blood group O, Jimenez, et al. [23] documented a higher plasma fibrinogen level in the patients with blood group $A B$ than in those with blood groups $A$, $B$ and $\mathrm{O}$.

Furthermore, the present study showed no significant differences in the mean level of both fibrinogen and platelet count in male and female participants of different $A B O$ blood groups studied. This confirms that gender differences do not alter the levels of platelet count and fibrinogen level in individuals of different $A B O$ blood group. This finding is corroborated by the results of similar studies [12,15,21]. 
Our study showed that in individuals of A blood group, plasma fibrinogen level correlates positively with Platelet count. This implies that in these individuals, when there is an increase in fibrinogen level an increase in platelet count should be expected and vice versa. This supports an earlier study by Aliberti, et al. [24] which found that plasma fibrinogen level was significantly correlated with the Platelet count. However, in our study, there were no significant correlations observed between platelet count and plasma fibrinogen level individuals of the other $A B O$ blood groups ( $A B, B$ and $O)$.

\section{Conclusion}

The present study revealed a significantly lower platelet count in $\mathrm{O}$ blood group participants than in $\mathrm{A}$ blood group individuals, this suggests the likelihood of higher risk of thrombocytopenia in blood group $\mathrm{O}$ individuals compared to blood group $A$ individuals. Also in individuals of $A$ blood group, fibrinogen level correlates positively with platelet count.

\section{Financial Support and Sponsorship}

Nil.

\section{Conflicts of Interest}

There are no conflicts of interest.

\section{References}

1. Demir T, Tezel A, Orbak R, Eltas A, Kara C, et al. (2007) The effect of $A B O$ blood types on periodontal status. Eur $\mathrm{J}$ Dent 1: 139-143.

2. Reilly $P$, Li M, He J, Jane F Ferguson, loannis M Stylianou, et al. (2011) Identification of ADAMTS7 as a novel locus for coronary atherosclerosis and association of $A B O$ with myocardial infarction in the presence of coronary atherosclerosis: Two genome-wide association studies. Lancet 377: 383-392.

3. Storry JR, Olsson ML (2009) The ABO blood group system revisited: A review and update. Immunohematology 25: 48-59.

4. Qureshi MA, Bhatti R (2003) Frequency of ABO blood groups among the diabetes mellitus type 2 patients. $\mathrm{J}$ Coll of Physicians Surg Pak 13: 453-455.

5. Gandara E, Kovacs MJ, Kahn SR, Wells PS, Anderson DA, et al. (2013) Non-O blood type influences the risk of recurrent venous thromboembolism. A cohort study. Thromb Haemost 110: 1172-1179.

6. Dentali F, Franchini M (2013) Recurrent venous thromboembolism: A role for ABO blood group? Thromb Haemost 110: 1110-1111.

7. Liumbruno GM, Franchini M (2013) Beyond immunohaematology: The role of the $A B O$ blood group in human diseases. Blood Transfus 11: 491-499.

8. Franchini M, Mannucci PM (2014) ABO blood group and thrombotic vascular disease. Thromb Haemost 112: 11031109.

9. Rios DRA, Fernandes AP, Figueiredo RC, Guimaraes DAM, Ferreira CN, et al. (2012) Relationship between ABO blood groups and von Willebrand factor, ADAMTS13 and factor VIII in patients undergoing hemodialysis. J Thromb Thrombolysis 33: 416-421.
10. Moeller A, Weippert-Kretschmer M, Prinz H, Kretschmer V (2001) Influence of ABO blood groups on primary hemostasis. Transfusion 41: 56-60.

11. Liu X, Chen X, Yang J, Guo R (2017) Association of ABO blood groups with von Willebrand factor, factor VIII and ADAMTS-13 in patients with lung cancer. Oncol Lett 14: 3787-3794.

12. Wang Z, Dou M, Du X, Ma L, Sun P, et al. (2017) Influences of $A B O$ blood group, age and gender on plasma coagulation factor VIII, fibrinogen, von Willebrand factor and ADAMTS13 levels in a Chinese population. Peer $\mathrm{J} 5$ : e3156.

13. Okeke CO, Okoro US, Babatunde A (2018) Variations in activated partial thromboplastin time and prothrombin time in individuals of $A, B, A B$, and $O$ blood groups. Iraqi $\mathrm{J} \mathrm{He}-$ matol 7: 85-89.

14. Amado E (1975) Health and normality. JAMA 232: 953-955.

15. Zhong M, Zhang H, Reilly JP, Chrisitie JD, Ishihara M, et al. (2015) ABO blood group as a model in arterial thrombosis. Arterioscler Thromb Vasc Biol 35: 1570-1578.

16. Doolittle RF, Spraggon G, Everse SJ (1998) Three-dimensional structural studies on fragments of fibrinogen and fibrin. Curr Opin Struct Biol 8: 792-800.

17. de Maat MP, Kastelein JJ, Jukema JW, AH Zwinderman, $\mathrm{H}$ Jansen, et al. (1998) -455/A polymorphism of the beta-fibrinogen gene is associated with the progression of coronary atherosclerosis in symptomatic men: Proposed role for an acute-phase reaction pattern of fibrinogen. Arterioscler Thrombs Vasc Biol 18: 265-271.

18. Harjai KJ (1999) Potential new cardiovascular risk factors: Left ventricular hypertrophy, homocysteine, lipoprotein(a), triglycerides, oxidative stress, and fibrinogen. Ann Intern Med 131: 376-386.

19. Magaly BP, Aldemir BO, Julia FC, Farida CBC, Neves WB, et al. (2009) Increased risk of venous thrombosis by $A B$ alleles of the $A B O$ blood group and factor $V$ Leiden in a Braziian population. Genetics and Molecular Biology 32: 264-267.

20. Ajayi OI, Ekakitie OO, Okpalaugo OC (2015) Differential rheology among $A B O$ blood group system in Nigerians. Afr Assoc Physiol Sci 3: 30-35.

21. Celik H, Duzenli U, Aslan M, Altiparmak IH, Kirmit A, et al. (2019) The relationship between platelet indices and ABO blood groups in healthy adults. J Clin Lab Anal 33: e22720.

22. Kremers RMW, Mohamed ABO, Pelkmans L, Hindawi S, Hemker HC, et al. (2015) Thrombin generating capacity and phenotypic association in $\mathrm{ABO}$ blood groups. PLoS One 10: e0141491.

23. Jimenez TM, Patel SB, Pineda AA, Tefferi A, Owen WG (2003) Factors that influence platelet recovery after transfusion: Resolving donor quality from $A B O$ compatibility. Transfusion 43: 328-334.

24. Aliberti G, Proietta M, Pulignano I, Del Porto F, Tammeo A, et al. (2010) Association between fibrinogen plasma levels and platelet counts in an outpatient population and in patients with coronary heart disease. Blood Coagul Fibrinolysis 21: $216-220$. 